\title{
Chemical mass balance, depositional efficiency, and rates of formation of seafloor massive sulfide deposits
}

\author{
J.W. JAMIESON ${ }^{1}$, D. SÁNCHEZ MORA ${ }^{1}$, B. PETERKIN ${ }^{1}$, T. \\ BARREYRE $^{2}$, J. ESCARTÍN ${ }^{3}$, MATHILDE CANNAT ${ }^{4}$
}

${ }^{1}$ Memorial University of Newfoundland, St. John's, Canada

${ }^{2}$ K.G. Jebsen Centre for Deep Sea Research, University of Bergen, Bergen, Norway

${ }^{3}$ Centre National de la Recherche Scientifique, Paris, France

${ }^{4}$ Institut de Physique du Globe, Paris, France

The sizes and rates of formation of seafloor massive sulfide deposits are partially dependent on the degree to which metals that are leached from oceanic crust by hydrothermal fluids or expelled from magmas are trapped at or below the seafloor. This depositional efficiency is thought to be primarily controlled by the extent of mineral precipitation caused by sub-seafloor mixing between the upwelling hydrothermal fluids and locally-infiltrating seawater. Constraints on this efficiency can provide a link between the volumes of hydrothermal deposits, past chemical fluxes, and, eventually heat fluxes associated with hydrothermal systems. So far, estimates of depositional efficiency, based on chemical mass balance calculations at a range of spatial scales, vary between $<1 \%$ to $>80 \%$.

Here, we present calculations of sulfide mass accumulation rates and estimates of depositional efficiencies from several active seafloor hydrothermal deposits. Accumulation rates are determined from estimates of deposit sizes from high-resolution mapping and $\mathrm{U}$-series radioisotope dating of the deposits. Efficiencies are calculated by comparing mass accumulation rates with metal fluxes calculated from vent fluid discharge rates and metal concentrations within endmember vent fluids.

Results from vent fields hosted on slow and imtermediate rate mid-ocean ridges and arc volcanoes indicate that mass accumulation rates are similar between vent fields from diverse tectonic settings. Calculated depositional efficiencies are significantly higher than previous estimates, and can vary between different vent complexes within single vent fields. Efficiencies are also metal-dependent, with metals associated with higher temperature fluids (e.g., $\mathrm{Cu}, \mathrm{Zn}$ ) having higher trapping efficiencies than lower temperature metals (e.g., Fe, $\mathrm{Mn})$. The balance between metal accumulation at the seafloor and venting of metals into the water column may have significant implications for metal budgets in the ocean. 